\title{
Concurrent Nasal Surgery with Mastoidectomy in Adults
}

\author{
Abhay Kumar Singh ${ }^{1}$, Himani Singh ${ }^{2}$, Harsimrat Singh ${ }^{3}$ \\ ${ }^{1}$ Assistant Professor, ${ }^{2}$ Post Graduate, ${ }^{3}$ Senior Resident, Department of ENT Saraswathi Institute of Medical \\ Sciences Hapur (U.P)
}

\begin{abstract}
Objective: To compare our findings with published success rates for mastoidectomy performed with concurrent nasal surgery

Materials and Method: The study was conducted from May 2017 - September 2019 in the E.N.T department of Saraswathi Institute of Medical Sciences, Hapur. We retrospectively reviewed 35 consecutively presenting patients who had undergone concurrent septoplasty and mastoidectomy with or without ossicular chain reconstruction. . The study consist of patients ranged in age from 18 to 50 years and were followed up for 1 - 24 months. Surgical success was defined as presence of an intact TM graft, well epithelized mastoid cavity without any evidence of middle ear effusion .

Results: Our 2 primary finding - graft survival rate of $91.42 \%$ and an overall surgical success rate of 77.1 $\%$ compare favourably with the results of other studies of outcomes of isolated mastoidectomies. Our data indicates that simultaneous performance of nasal surgery and mastoidectomy is feasible in adults. Nasal packing has got short term effect on ET dysfunction but rarely severe enough to cause symptoms or middle ear effusion. Concurrent approach is useful in TM graft survival or mastoid cavity epithelisation in long term overall surgical treatment success. The concurrent approach requires only single time administration of general anaesthesia, cost effective treatment, improved overall symptomatic relief from nasal and ear symptoms.
\end{abstract}

Keywords: Central Perforation, Hearing Improvement, Mastoidectomy, Septoplasty, Tubotympanic CSOM

\section{Introduction}

Patients with chronic otologic disease frequently have coexistent nasal pathology at times which can cause or worsen middle ear problems secondary to dysfunction of the Eustachian tube. Sino nasal causes of Eustachian tube dysfunction include upper respiratory tract infection, sinusitis, allergic rhinitis, adenoid hypertrophy, a nasopharyngeal mass, exposure to tobacco smoke, extra esophageal reflux, cleft palate, radiation treatment, ${ }^{1}$ and nasal septal deviation. ${ }^{2}$ ET dysfunction can result in

\section{Corresponding Author:}

\section{Dr Himani Singh}

Post graduate Department of ENT

Saraswathi Institute of Medical Sciences, Hapur (U.P)

E-mail: himanisingh2326@gmail.com chronic negative middle ear pressure, which can cause tympanic membrane retraction, chronic otitis media with effusion and cholesteatoma. Those who have argued against simultaneous nasal surgery and tympanoplasty have cited a transient decrease in middle ear pressure associated with rhinologic procedures and postoperative nasal packing that may place the TM graft under tension and thereby increase the risk of reperforation..$^{3-6}$

\section{Aim}

We compare our findings with published success rates for mastoidectomy performed with concurrent nasal surgery

\section{Patients and Method}

Retrospectively reviewed 35 consecutive cases 
who had undergone concurrent septoplasty and mastoidectomy with or without ossicular chain reconstruction (OCR) from May 2017 to September 2019 at Saraswathi Institute of Medical Sciences, Hapur, U.P.

Surgical success was defined as presence of an intact TM graft,well epithelized mastoid cavity without any evidence of middle ear effusion. The study consist of 35 patients ranged in age from 18 to 50 years and were followed up for 1 - 24 months. The surgeries were performed under General Anesthesia (average time 2 to 4 hours). Patients were discharged from the hospital with oral medications following one or two days of hospitalization. They receive antibiotics for 10 post operative days and then a topical antibiotics was used as indicated and nasal douching and cleaning was regularly advised and done. Patients were called for control visits on $7^{\text {th }}$ day, $14^{\text {th }}$ day, $21^{\text {st }}$ day, $28^{\text {th }}$ day, $2^{\text {nd }}, 3^{\text {rd }}$ and 6 month and every half early as per the requirement and the type and nature of mastoidectomy done.

Risk factors for surgical failure include ET dysfunction, low middle ear volume, smoking, disease in the opposite ear, a large perforation, myringosclerosis, extensive cholesteatoma, particular surgical technique.

\section{Statistical Analysis}

Data were analyzed using PASW version 17.0 (SSPS Inc., Chicago, IL, USA) software. The statistical analysis of categorical variables was performed using a chi-square test. A $p$ value less than 0.05 was considered significant.

\section{Discussion}

The indications for mastoidectomy included all necessary preoperative work up, tests and evaluation.
On the most basic level, a successful tympanoplasty requires survival of the TM graft without reperforation. However, some authors have required additional factors, such as middle ear aeration 7,8 . TM perforation occured in 25 out of 35 patients (71.4\%). Unhealthy middle ear mucosa with hypertrophy or granulations despite conservative treatment occurred in 25 patients (71.4\%). Chronic otorrhea in 30 patients (85.7). Cholesteatoma in 20 patients $(57.14 \%)$. Adhesive otitis media in 3 patients $(8.5 \%)$. The sole graft failure occurred in 2 patients after 3 months and a recurrence of cholesteatoma seen in one CWUTM after 18 months post operatively. Different types of otological procedures performed included. Primary canal wall up Tympanomastoidectomy which includes cortical mastoidectomy (CWUTM) in 20 patients $(57.1 \%)$. A primary CWUTM with OCR in 17 cases (48.5\%). A type 1 tympanoplasty with CWUTM in 3 patients . 3 revision CWUTM with OCR . Canal wall down tympanomastoidectomy (CWDTM) with OCR in 15 patients. Revision CWDTM with OCR in 3 patients. Surgical success seen in 32 out of 35 cases (91.4\%)

Different techniques of cartilage tympanolasty were used to reconstruct neo tympanic membrane grafting. 2 patients developed small central perforation after 3 months due to otitis media with effusion were advised for a revision surgery. 1 patient developed postoperative otorrhea. 6 patients were diagnosed with acute otitis media responded well with conservative treatment (cefpodoxime, amoxycillin, nasal decongestants, mucolytics etc) 


\section{INDICATIONS OF MASTOIDECTOMY WITH NASAL PATHOLOGY}

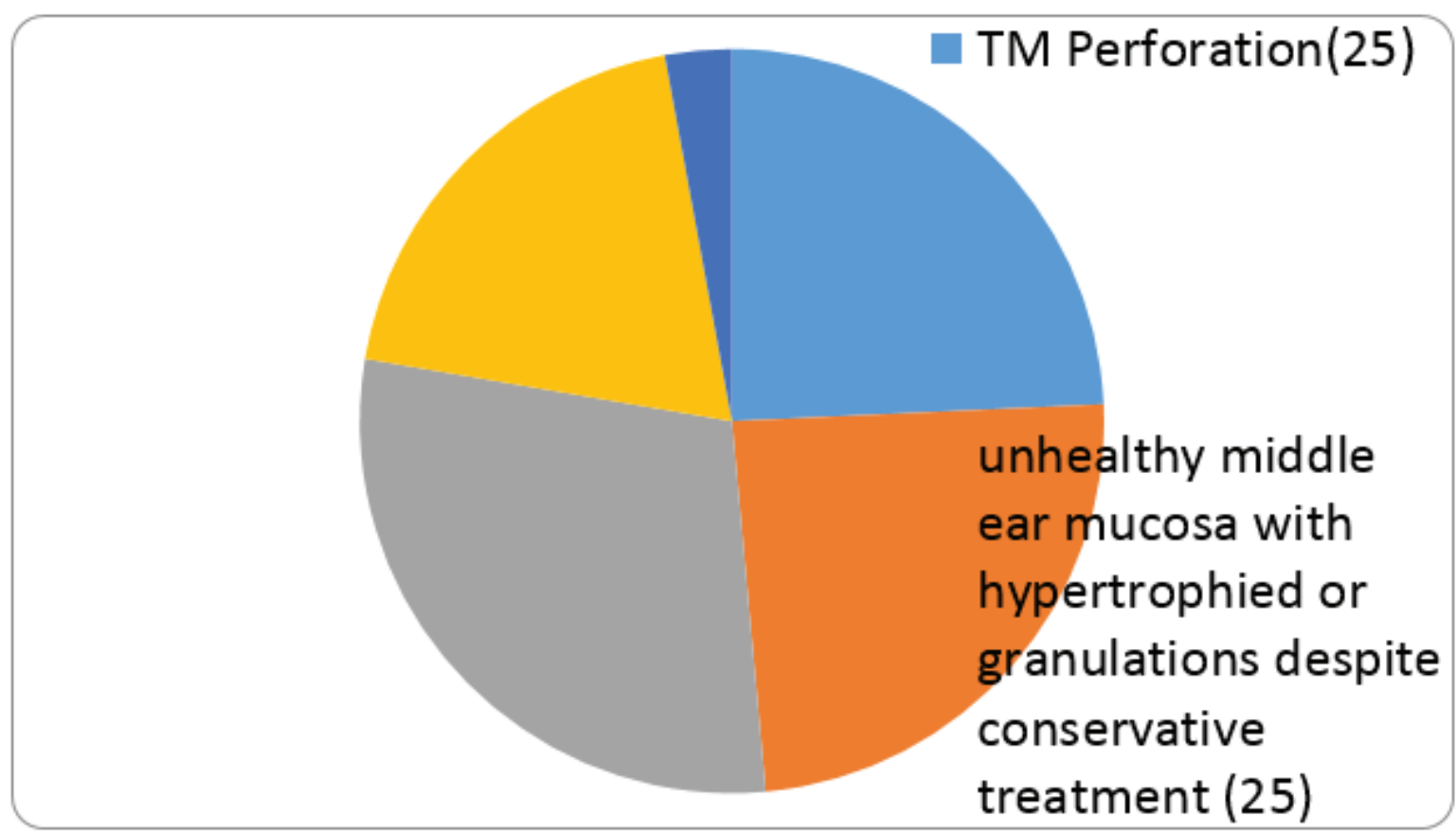

\section{DIFFERENT OTOLOGICAL PROCEDURES PERFORMED}

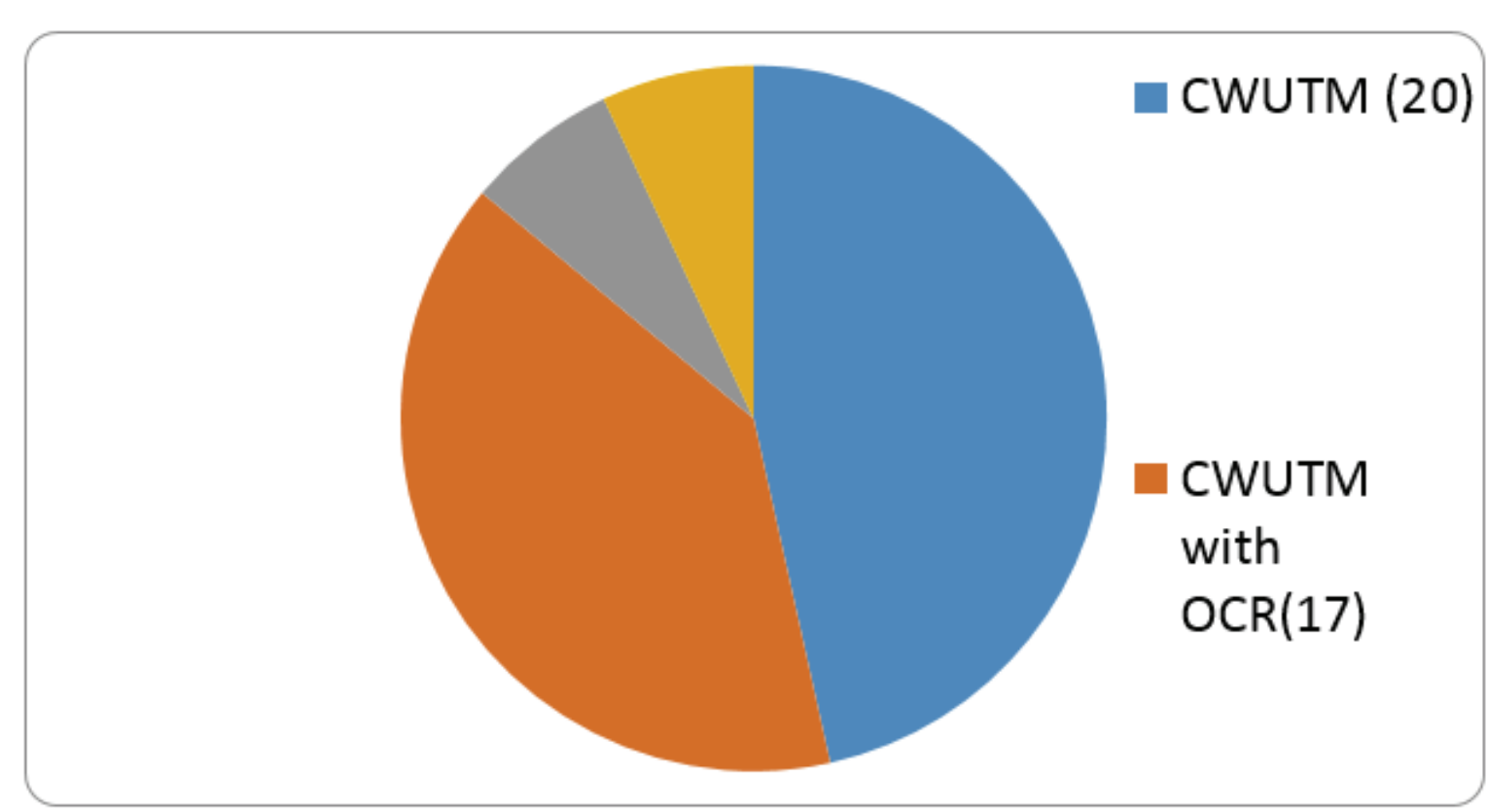

\section{INTERPRETATIONS AND FINDINGS}

A graft survival rate of 92 percent seen after 3 months to follow up till 24 months in CWUTM. A mastoid cavity EPITHELIZATION with well uptaken graft is seen in 93 percent of CWDTM. Overall success rate of 91 percent seen after 24 months of follow up. No extra cost analgesia, antibiotics and not much pain is experienced by the patients undergone concurrent nasal surgery and mastoidectomy 


\section{RESULTS AND INTERPRETATION}

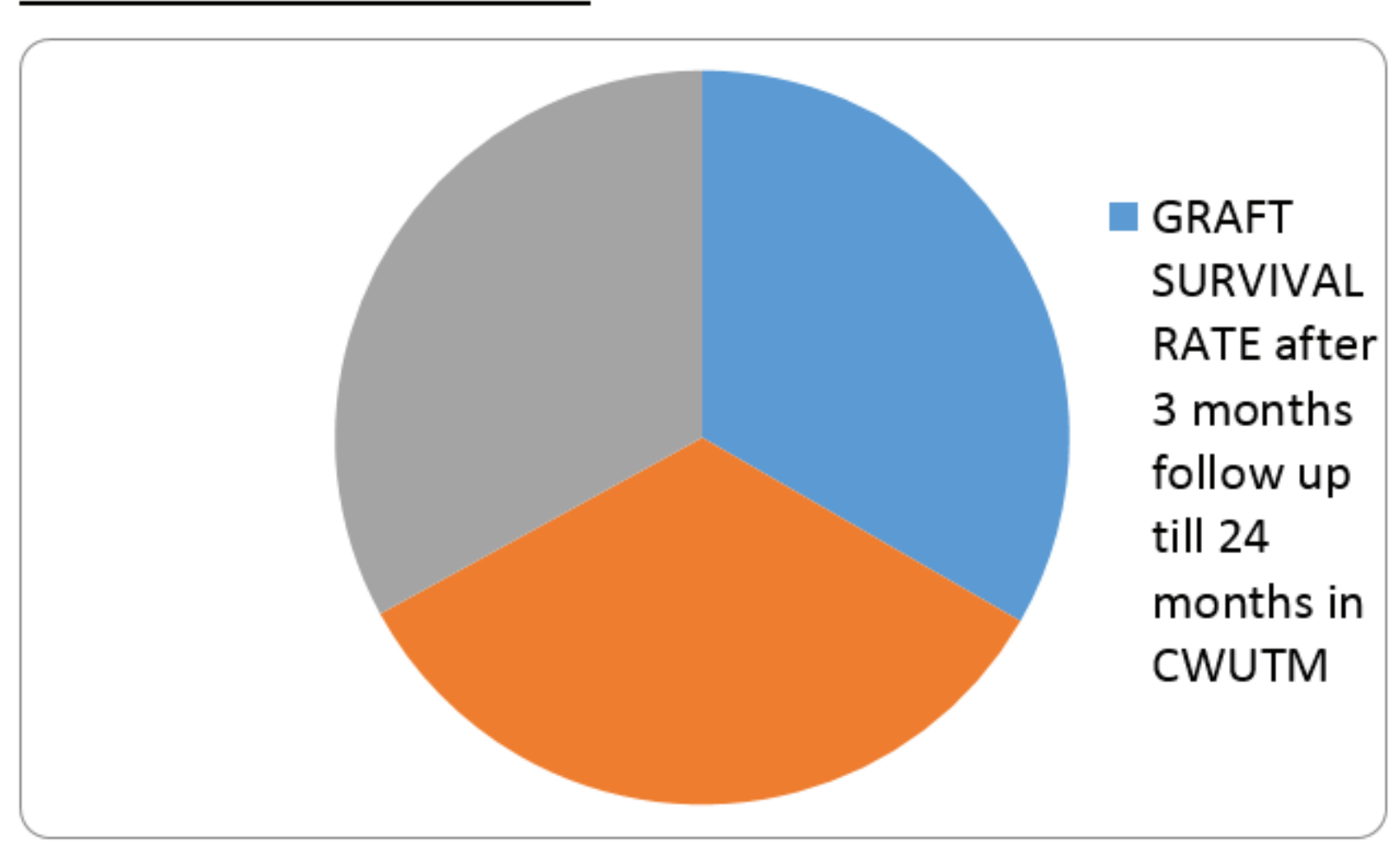

\section{Conclusions}

Concurrent approach is useful in TM graft survival or mastoid cavity epithelization in long term overall surgical treatment success. The concurrent approach requires only single time administration of general anesthesia, cost effective treatment, improved overall symptomatic relief from nasal and ear symptoms.

Our data indicates that simultaneous performance of nasal surgery and mastoidectomy is feasible in adults. Nasal packing has got short term effect on ET dysfunction but rarely severe enough to cause symptoms or middle ear effusion. Early peritubal inflammation can be managed very well conservatively post op using antibiotics, analgesics, decongestants etc. Adequate gel foam bed $\&$ wise selection of cartilage strut designing \& placement in middle ear holds true to long term success of surgery. 
Right cortical mastoidectomy + Type 1 cartilage shield tympanoplasty with endoscopic septoplasty and spurectomy (9weeks follow up) [Figure 1]
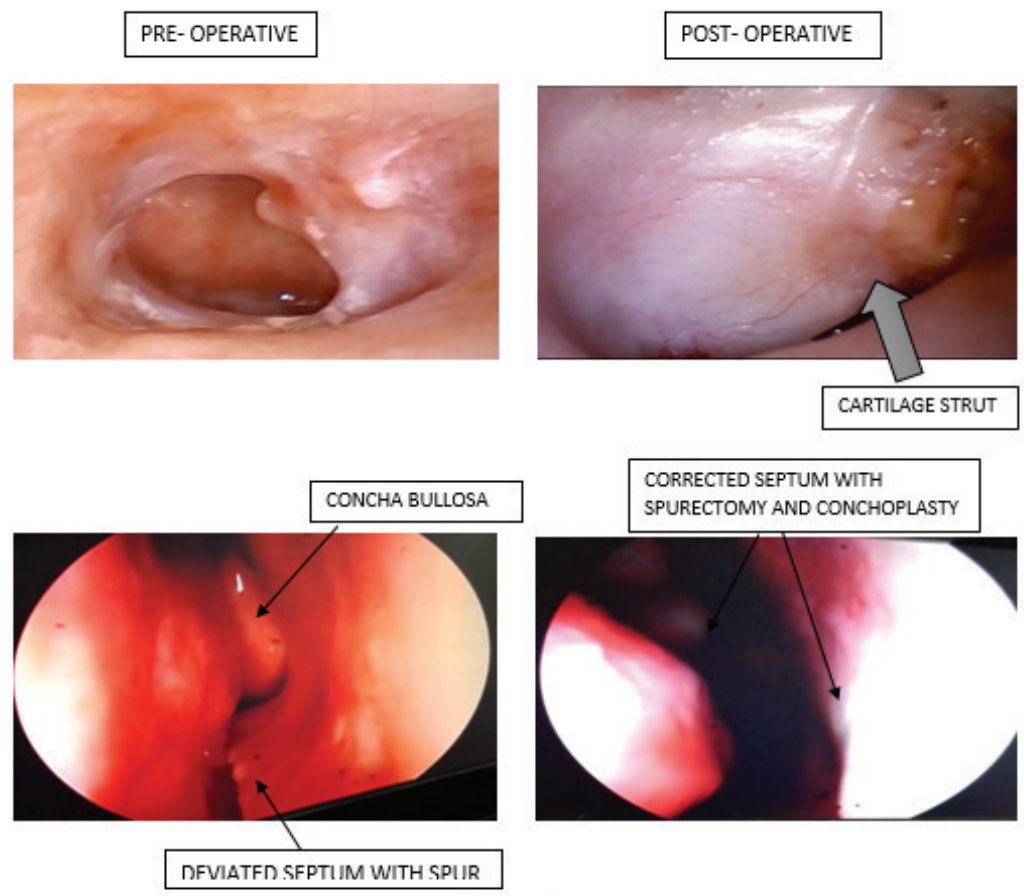

[Figure 1]

Left Cortical Mastoidectomy with type 1 cartilage tympanoplasty (3 months follow up) with endoscopic septoplasty with spurectomy [Figure 2]

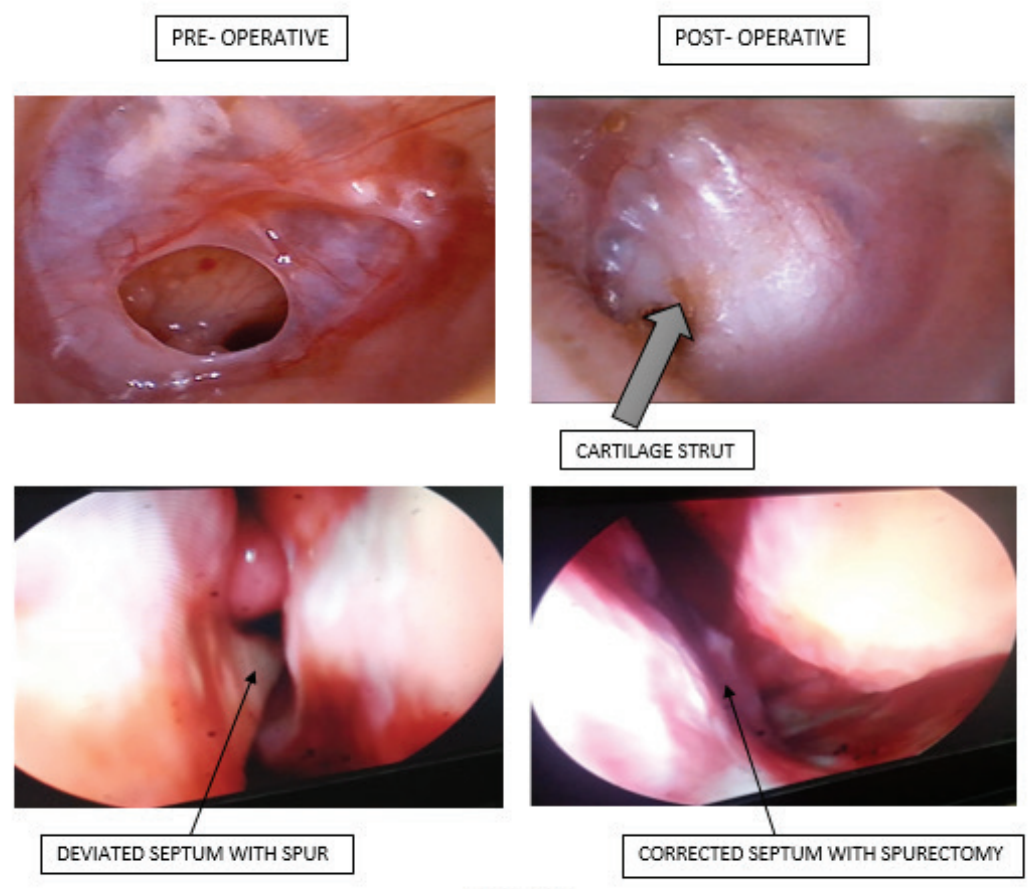

[Figure 2] 
Acknowledgment- The authors are thankful to chairman and managing member of Saraswathi institute of medical sciences, Hapur, U.P for their encouragement.

Ethical Clearance- Taken from ethical committee of institute

Source of Funding- Self

Conflict of Interest - Nil

\section{Referances}

1. Seibert JW, Danner CJ. Eustachian tube function and the middle ear. Otolaryngol Clin North Am 2006;39(6):1221-35.

2. McNicoll WD. Uncomplicated eustachian tube dysfunction: The site of the nasal septal deformity. J R Nav Med Serv 1982;68(1):23-9.

3. Koch U, Herberhold C, Opitz HJ. Middle ear pressure after rhinoplasty surgery [author's transl; in German]. Laryngol Rhinol Otol (Stuttg) 1977;56(8):657-61.
4. Laszig R. Development of pressure in the middle ear after nasal operations [in German]. HNO 1985;33(4):187-9.

5. Becker W, Opitz HJ. The problems of simultaneous tympanoplasty and adeno-tonsillectomy [author's transl; in German]. Laryngol Rhinol Otol (Stuttg) 1978;57(3):203-9.

6. Maier W, Krebs A. Is surgery of the inner nose indicated before tympanoplasty? Effects of nasal obstruction and reconstruction on the eustachian tube [in German]. Laryngorhinootologie1998;77(12):682-8.

7. Megerian CA. Pediatric tympanoplasty and the role of preoperative eustachian tube evaluation. Arch Otolaryngol Head Neck Surg 2000;126(8):103941.

8. Pinar E, Sadullahoglu K, Calli C, Oncel S. Evaluation of prognostic factors and middle ear risk index in tympanoplasty. Otolaryngol Head Neck Surg 2008;139(3):386-90. 